\title{
E-Marketing; Innovations And Future Prospect In Pakistan
}

\author{
Umer Farooq \\ University of Management and Technology Lahore \\ Junaid Akhther \\ University of Management and Technology Lahore \\ Samra Naveed \\ University of Management and Technology Lahore
}

\begin{abstract}
With the extraordinary development of innovation in worldwide world, web assumes a fundamental job in all the real aspects of our life and enterprises. With-in few ticks we can investigate sufficient data which will help in conceptualizing numerous assignments in nanoseconds and understanding this intensity of web, showcasing isn't a long ways behind to utilize it as a driving channel to achieve the worldwide region. $e$ Marketing otherwise called computerized showcasing contains the utilization of virtual advanced space with an extent of cooperation, this computerized space is been utilized by the advertiser to advance and sell the items and administrations. This web based advertising assumed an essential job to inspire the distinctive financial areas with uncommon underline on showcasing. Considering this is a financially savvy, quick and adaptable approach to contact the crowd of worldwide Diasporas, e-promoting bring significant business gains. Anyway e-promoting has its own arrangements of constraints that incorporate a greater amount of tech contact rather than faculty contact, guaranteeing the wellbeing and security with part of protection encroachment. The paper begins with characterizing the idea, birthplace, how unique e-advertising is from customary promoting, $7 \mathrm{C}$ 's of e-showcasing, various systems of e-showcasing the favorable circumstances, impediments, its future and end.
\end{abstract}

Keywords; E-Marketing, Advertising, promotions Market, Online market,

\section{INTRODUCTION}

The trend of E-Marketing enters in Pakistan after 2000. In the past, peoples do not preferred the E-Marketing, but the passage of time E-Marketing change the prospective of persons. The new technology of E-Market attracts the peoples. The new method and techniques used for EMarketing include advertisement, social media, massages, e-mails, search engine optimization and so on. The best benefit of E-Marketing is to connect all over the world whose connect with this market and reduce the distance.

E-Market established in 1994, when hotwired sold his first electronic add to the certain advertisers. United State of America (USA) revenue grew in 2001 about \$7.1 Billion or 3.1 percent of overall advertising. E-marketing collect $\$ 2.1$ billion through advertisement in (Holahan 2006).

The main content of E-Marketing is to reach the customers through the different channels where they spend time in shopping, advertising, education, socialization or business online. The Internet has prompted an inexorably associated condition, and the development of Internet use has brought about the declining appropriation of conventional media: TV, radio 
and papers. Promoting in the associated condition and utilizing that availability to market is EMarketing. E-showcasing move and push ahead more refine approach and better technique to gather data is required.

E-Market changed the structure and performance of the marketing. E-Market changed the rules and regulations of the market trend and work performance. Internet marketing is a demonstration that uses electronic channels to distribute photos, objects or organizations to potential customers. Online marketing technologies and strategies include email, email, advertising, and site rationalization. It is just a sign of more.

Internet marketing is a procedure that helps develop an organization's notoriety and exposure online by utilizing an assortment of internet tools and arrangements. Web based promoting varies from conventional showcasing, which has generally included mediums like print, board, TV and radio ads.

.Before online exhibiting channels built up, the cost to publicize things or organizations was much of the time prohibitively expensive, and by and large difficult to evaluate. Consider national TV advancement campaigns, which are assessed through customer focus get-togethers to choose measurements of brand care. These methodologies are moreover not proper to controlled experimentation. Today, anyone with an online business can share in electronic displaying by making a website and building customer verifying endeavors at for all intents and purposes zero cost. Those exhibiting things and organizations also can attempt various things with improvement to adjust their campaigns' adequacy.

\section{LITERATURE REVIEW}

E-marketing also called the internet marketing include different methods or techniques as follows:

The data was collected via articles. E-market shopping is very slow due to lack of consumers trust, security, financial and privacy. Security impact E-market purchasing of consumers and finance refer to monetary loss due to shopping on E market.

E-showcase shopping demonstrated that accommodations and efficient are the primary reasons that persuade the buyers to shop on the web. E-advertise decreased the time and endeavors of purchasers in purchasing behaviors. (Schaup and Belanger 2005) contend that E market has made discovering dealer simpler by chopping down an exertion and time. E shopping is more player than the customary shopping because of offices and simple to utilize and picking up fame in Pakistan.

Social media change every think of our lives. In fact "The method of statement in the $21^{\text {st }}$ century, enabling us to express our beliefs, ideas and manner in an absolute new way."

Social media have a large influence on corruption and realize that without perfect idea and best social media strategies they have no choice to stay quietly and quickly changing electronically freedom.

Social media is best used for small business to promote the products and services and low competitive benefits. Social media help to control business any where any time without any physical location. In E market social media help to new business holders to provide a guideline and how to control the business via E market. E advertising is different to TV ads. It wants it to much creativity. E-ads do not force to focus on ads. E-ads used to put a message on website to pay attention the internet users. 
Sales promotion and public relations are the communication tools available to the marketers through the advertisement. Today advertisement definition is communication process, economical and social patterns, information patterns and relation patterns. Advertisement established is used to awareness of products and services in the customers mind and develop knowledge about it.

Advertisement provides main tools in product awareness/knowledge and suitable conditions in the mind of customers to take final step. Advertisement is a primary goal to reach to the customers and encourage to buying a products.

Advertisement is the most effective tool of communication to emotionally motivate customers to purchase the product. Advertisement is used to create brand knowledge and selection of product and services. Advertisement is the positive goal that affects attitudes towards the brands and increase in purchasing than the positive emotional advertisement may be the best tool for advertisement.

Environment might effect on buying patterns of consumers. Environment provides various kind of experience for customers and used for promotions and selling various kinds of goods ads services. In our society, culture desires explain the impulse and moments.

\section{RESEARCH METHODOLOGY}

Research strategy In request to examine the significance and the job of coordinated showcasing correspondence for web dynamic associations, the accompanying examination targets has been figured:

- To examine the general effect of web innovation on the showcasing correspondence process and the conduct of spectators.

- To define the significance/s of coordinated internet promoting correspondence.

- To recognize the promoting correspondence cooperative energies permitted by the web.

- To recognize the difficulties raised by the web for the coordinated correspondence process.

- To plan an engineered model portraying the structure and working of an incorporated web based advertising correspondence framework.

A progression of auxiliary wellsprings of information have been gotten to in the first occurrence, so as to gather general data about the advancement of the IMC idea, web qualities, online correspondence and online crowds.

In the second phase of information accumulation, a progression of semi-organized meetings have been directed with promoting or correspondence administrators of web dynamic UK retailing firms. Utilizing the contact data gave on their sites, 70 UK retailers represented considerable authority in buyer items (sustenance, drinks, beauty care products, garments, shoes) have been reached by telephone or by email, and welcomed to take part in the examination. 34 of thefirms have reacted positively, yet just 29 meetings could be composed in view of time confinements in the interviewees' program. The up close and personal meetings occurred during February-May 2005, and kept going somewhere in the range of 40 and an hour. The subjects of discourse incorporated the idea of coordinated promoting correspondence, the chances and difficulties made by the web concerning the corporate correspondence model, and the specific vital model that can upgrade the web based advertising correspondence process. This methodological methodology endeavors to actualize practically speaking the suggestion of Kitchen and Schultz (1999) to explore and examine the response of different professionals to the IMC idea. 
A review of important information is carried out physically, taking into account the number of sessions and the purpose of the investigation.

The effect of the web innovation on advertising correspondence The quick advancement of the web over the most recent ten years has changed the old style correspondence methodology (Blattberg and Deighton, 1991; Holtz, 1999), as a result of three specific and concurrent qualities that separate it from some other correspondence channel:

\section{- Intuitiveness :}

The web offers different conceivable outcomes of intelligent correspondence, acting as an interface, yet in addition as a correspondence operator (permitting an immediate association among people and programming applications).

\section{- Straightforwardness :}

The data distributed online can be gotten to and seen by any web client, except if this data is specially ensured.

\section{- Memory :}

The network is a data transmission channel, yet in addition for putting away data - as such, the data distributed on the web stays in the memory of the system until it is eradicated.

\section{The group of spectators is associated with the associations:}

The conventional correspondence channel was uni-directional - the establishments imparted and the crowds devoured the data. Notwithstanding when correspondence was viewed as a two-way process, the organizations had the assets to send data to crowds through a wide pipeline, while the spectators had just a minute pipeline for imparting back to the establishments (Ihator, 2001). Presently, the correspondence channel is a system, not a pipeline. This system has shut the hole among organization and group of spectators. Everyone associated with sending Integrated internet promoting correspondence 173 the message - the organization, its CEO, its correspondence chief, the outside correspondence office - are just a single tick far from the group of spectators. Somewhat, communicators have gotten a handle on and even grasped this new vicinity, actuality shown by the huge number of sites which show "Get in touch with Us" catches and connections (Blattberg and Deighton, 1991). Nonetheless, in the greater part of the cases, these new offices are not completely utilized. The simplicity of correspondence has prompted an exponential increment in the quantity of approaching messages, yet numerous associations have not expanded the assets expected to manage them. In the new model, communicators must connect with individuals from the group of spectators on a balanced premise (Holtz, 1999).

Thinking about the idea of the system, if the crowd is a single tick far from the organization, it is additionally a single tick far from different individuals from the group of spectators. Today, an organization's movement can be talked about and bantered over the web, without the information of that association. In the new situation each person is a communicator, and the organization is simply part of the system (Shankar and Malthouse, 2007)

\section{The group of spectators approaches other data:}

Before, as a result of the gradualness and trouble to get to specific data, the communicator had the option to create an impression with the sensible assurance that it would be unthinkable for the normal crowd part to challenge it. Today, it is anything but difficult to get to different wellsprings of data over the web. Any announcement made can be dismembered, dissected, talked about and tested inside hours by intrigued people. 


\section{Spectators pull data:}

The world is expanding the number of available communication channels exponentially (Holtz, 1999). Today we receive messages from many media stations, such as email, voice mail, fax, pager, telephone, official alerts, interim messages, multi-channel television, radio and Internet radio. A media that uses an effective communication channel for professionals is simply a telephone that understands how it is organized by most viewers. Organizations, on the other hand, provide different models for downloading data according to their interests and needs, not allowing viewers to recognize the messages that the communicator must send. When they are organized, viewers should be able to access the data if they can find them and they need to change or customize them (Rowley, 2001, 2004).

\section{Absence of vis-à-vis contact:}

\section{E-MARKETING PROBLEMS}

Absence of individual contact is another inadequacy of web based advertising which has been tended to in web based showcasing examination and writing (Goldsmith and Goldsmith, 2002; Phau and Poon, 2000). Web exchanges include no epitomized, individual communication and this is the reason a few clients consider electronic methods of giving client administration unoriginal and appreciate the experience of shopping in a blocks andphysical store. They want to converse with store work force in an eye to eye way, contact the related item with their hands, and associate with different clients. Virtual commercial center can't accommodate this capacity of disconnected shopping and needs close to home cooperation. To be increasingly explicit "for the sorts of items that depend vigorously on structure individual connection among purchasers and venders, for example, the selling of life coverage, and the kind of items that requires physical examination, Internet promoting possibly less fitting" (Kiang and Chi, 2001)

Up close and personal contacts isn't significant just on account of uncommon kinds of items; here culture is additionally a pertinent variable. For instance Rotchanakitumnuai and Speece (2003) can be alluded who have featured the absence of individual contact in online exchanges. In addition to other things, they allude to Asian societies in which individual connections are of an unmistakable esteem and this, together with the exchange setting, is regularly assumes an essential job in guaranteeing the accomplishment of monetary arrangements.

\section{Security and Privacy:}

Data protection is among significant themes to be thought about in the present advancing electronic world. 225). Current customer information, whether you agree or not, can certainly be passed on to other organizations. Even simpler personal information, such as user names and passwords, is insensitive to programmers (Lantos, 2011: 74). Other related problems include mineral springs and their formation, which is one of the reasons for the vulnerability of most online customers (Drozdenko and Drake, 2002: 317). These security and protection issues are one of the difficulties of online advertising. Successful promotion on the Internet depends on solving the problems associated with this method. James W. Peltier et al. (2010) assumes that you can work with the advertising creation module, and suggests "duplication on this topic should be presented at intermediate levels and at different levels of inclusion".The significant measurement regarding security is the decision or assent. This measurement has its underlying foundations in this conviction that purchasers whose information have been gathered by the individual organization ought to have power over the manners by which their data is utilized. Particularly they likewise ought to be conceded the privilege to have control "over how their own data is utilized past the reason for which it was gathered" (in the same place, 228). 


\section{Absence of trust :}

"Solidly related with the issue of security and insurance is the issue of nonappearance of trust concerning customers which has been seen an unprecedented test in travel of web displaying advancement. Also, it is the inspiration driving why ?online trust is developing in significance as a subject of study and its effect on web showcasing methodologies is increasing"(Urban et al, 2009: 179). Bart et al (2005) features frost trust in virtual state as pursues: "online trust incorporates customer view of how the webpage would convey on desires, how credible the website's data is, and how much certainty the website directions" (134).

Despite the rapid development of online transactions, some still question the strategy of electronic payments and still ask questions about whether they delivered the goods they purchased. Redistributing online content will result in negative behavior or suspicion of online sharing.

\section{Overcoming the geographical barrier.}

\section{CRITICAL REVIEW}

One of the highlights of online presence is the elimination of all land restrictions from receipts and sales demonstrations. Thus, the Internet offers overall performance that cannot be achieved at a much lower price. While there are a number of exceptions to the major global associations with huge costly for the general press, substantial progress was made on the Internet, and small organizations were able to evaluate this type of performance. Overcoming geographic barriers, advertisers can now represent objects and manage a diverse collection of customers using basic network access requirements (Mohammed, 2010: 2)

\section{4/7 availability:}

The Internet is available 24/7 and 7 days a day, so you can provide convenient data to your customers (Lane, 1996). By creating an online store, customers can provide data and shop online when they want day or night. Thus, there is no time limit, because in online organizations there is no exclusive closing and open case. Individuals can visit the real market after viewing the network or other routes. You can surf the net with aggressive fees due to physical visits to the store. (Sharma, 2011: 203). There is also no doubt that online purchases are becoming more and more useful, since there is no reason to leave the house, visit various stores and check out product and cost changes. Buyers can shop much more successfully than at home.

\section{Cost-Affectivity:}

It's implied that, contrasted and conventional publicizing media channels, which are very asset devouring, web based advertising through web is plainly financially savvy and achieved its destinations at a small amount of (Paul, 1996; Hamil, 1997; Buhalis and Law, 2008; Poon and Jevons, 2010). For example clearly the expense of propelling an advertisement online is far not exactly putting a promotion in a magazine or on an announcement. The expense of building up one's virtual nearness, organizing with different foundations and correspondence with buyers is altogether low. Significantly web showcasing empowers the organizations to spare their assets, an angle which is profoundly valued by organizations since the internet advertising efforts don't require gigantic venture.

\section{Personalization:}

Personalization which accompanies customization is another significant viewpoint impossible to miss to advertising on the web through web. So internet showcasing is a customized advertising which is additionally called promoting to the Segment of One or "coordinated promoting" (Peppers and Rogers,1993). In any case,Personalization alludes to fitting items and 
administrations to clients' inclinations dependent on their on the web, enlisted buy history. Truth be told "since electronic cooperation with clients permits the social affair of nitty gritty data on the necessities of every individual client, firms can consequently tailor items and administrations to those individual needs" (Karavdic and Gregory, 2005:80). This procedure brings about inventory altered items to clients. Thusly clients are send customized messages which creates a lot more noteworthy effect contrasted and impersonalized, nonexclusive messages send unpredictably to post box of clients

\section{SUMMING UP}

Web has risen as an upheaval in generally speaking part of our life beginning from more extensive economy to promoting. This examination mirrors the idea of e-promoting with current techniques and its predominance over customary showcasing with set of focal points includes wide inclusion of worldwide populace, achieving the objective arrangement of clients and to get separate criticism from them about the item hence making more noteworthy chance to draw in with them with snappy and powerful outcomes in ideal expense and adaptable outcome., Web has revolutionilized each piece of life including economy and displaying. Introducing genuine frameworks and techniques for online publicizing, this examination has uncovered understanding upon conditions and challenges of Internet. The critical focal points web has are its Empowering sway, Elimination of geographic impediments, 24 hours/seven days availability, Cost-affectivity, Tractability, and Personalization. Be that as it may, usage of Internet in the field of advertising includes uncommon impediments, for example, Problem of honesty, Lack of eye to eye contact, Security and Privacy, Lack of trust. Except if these double normal for Internet have not been thought about, it can't be conveyed to further its full potential benefit. An internet showcasing system educated by bits of knowledge from such a thought would ensure its money related goals.

\section{Reference:}

Bart et al, Advertising and Promotion, An Integrated Marketing Communications Perspective, 2005.

Russell Brunson, DotCom Secrets, 2015.

Beldona, S. (2005) Cohort Analysis of Online Travel Information Search Behavior:1995-2000, Journal of Travel Research, 44 (2):135-42.

Bhui, K. and Ibrahim, Y. (2013) Marketing the_radical“": Symbolic communication and persuasive technologies in jihadist websites, Transcultural Psychiatry, vol. 50(2) 216-234.

Blech, G. E. and Blech, M. A. (2012) Advertising and Promotion: An Integrated Marketing Communications Perspective, 9th Edition.

Buhalis, D. and Law, R. (2008) Progress in information technology and tourism management: 20 years on and 10 years after the Internet-The state of e-Tourism research, Tourism Management, Volume 29(4): 609-623.

Chaffey, D. et al (2000) Internet Marketing: Strategy, Implementation and Practice, Financial Times Prentice Hall. Charlesworth, A. (2009) Internet Marketing: a practical approach, Butterworth Heinmann / Elsevier.

Clow, K. E. and Baack, D. E. (2013) Integrated Advertising, Promotion, and Marketing Communications. Prentice Hall.

Deighton, J. (1997) Commentary on exploring the implications of the Internet for consumer marketing, Journal of the Academy of Marketing Science 25:347-51.

Dholakia, R. R. and Kshetri, N. (2004) Factors Impacting the Adoption of the Internet among SMEs, Small Business Economics, Volume 23(4): 311-322.

Drozdenko, G., \& Drake, P.D. (2002) Optimal database marketing: strategy, development, and data mining, Sage Publications.

Godes, D. and Mayzlin, D. (2004) Using Online Conversations to Study Word-of-Mouth Communication, Marketing Science, Volume 23(4): 545-560. 
Granitz, N. and Greene C. S. (2003) Applying E-Marketing Strategies to Online Distance Learning Journal of Marketing Education, Vol. 25 No. 1:16-30.

Gretzel, U. (2006) Consumer Generated Content-Trends and Implications for Branding, e-Review of Tourism Research, 4 (3): 9-11.

Hamil, J. (1997) The Internet and international marketing, International Marketing Review, Vol. 14 Iss: 5, pp.300 323.

D.E. (1996), "The inevitability of integrated communications”, Journal of Business Research, Vol. 37 No. 3, pp. 13947.

D.E. (2003), “Opinion piece: the next generation of integrated marketing communication”, Interactive Marketing, Vol. 4 No. 4, pp. 318-9.

D.E. and Kitchen, P.J. (2000a), “A response to "Theoretical concept or management fashion?'”, Journal of Advertising Research, Vol. 40 No. 5, pp. 17-21.

D.E. and Kitchen, P.J. (2000b), Communicating Globally: An Integrated Marketing Approach, Macmillan Press, London.

D.E., Tannenbaum, S.I. and Lauterborn, R.F. (1993), Integrated Marketing Communication: Putting it Together and Making it Work, NTC Business Books, Lincolnwood, IL.

Semenik, R.J. (2002), Promotion and Integrated Marketing Communications, Thomson Learning, Cincinnati, OH. 